\title{
The Effect of Bupivacaine on Pain Relief After Lumbar Decompression Surgery
}

\author{
Hamid Kayalha ${ }^{1}$, Asghar Karbord ${ }^{2 *}$, Seyyed Mehran Molavi Shirazi ${ }^{3}$, Seyyed Mohsen Hassani Barzi ${ }^{3}$ and \\ Shahram Rastak ${ }^{4}$ \\ ${ }^{1}$ Department of Anesthesiology, Faculty member of Medicine College of Qazvin University of Medical Sciences, Iran \\ ${ }^{2}$ Qazvin University of Medical Science, Iran \\ ${ }^{3}$ Department of Neurosurgery, Qazvin University of Medical Sciences, Iran \\ ${ }^{4}$ Department of Anesthesiology \& Faculty members of surgical technologist group of paramedical college, Qazvin University of medical science, Iran
}

*Corresponding author: Asghar Karbord, MSc Epidemiology \& Faculty members of Surgical Technologist group of paramedical college, Qazvin University of medical science, Qazvin, Iran.

\section{Abstracts}

Aim: there are many reports about the efficacy of analgesics in reducing postoperative pain after lumbar decompressive surgery. This study aimed to investigate the effect of subdermal and intramuscular injection of bupivacaine on the severity of postoperative pain after lumbar decompression surgery.

Material and Methods: in this randomized double-blind trial, 50 patients who candidate for lumbar decompressive surgery elective for this them. Bupivacaine $(0.25 \%)$ in the intervention group and normal saline $(40 \mathrm{ml})$ in the control group were injected subcutaneously and intramuscularly. Factors of age, size of surgical cutting, number of operating spaces, duration of operation, the rate of need to analgesia, and the severity of pain at times of 3,12 and 24 hours after surgery were assessed.

Results: the severity of pain in Bupivacaine group, in hours 3,12 and 24 after postoperative surgery was less than control group (P value $<0.05)$. Also, there was no significant difference between the two groups in terms of mean pain intensity using repeated measure design ( $\mathrm{P}$ value $<0.05)$. But within Bupivacaine group, pain severity significantly decreased during the 24 hours after surgery. $(p<0.05)$

Conclusion: Although bupivacaine $(0.25 \%)$ results in reducing pain after surgery, more studies are recommended to investigate the effect of bupivacaine in combination with other drugs in cases of lumbar decompressive surgery. Also, it reduces pain during the 24 hours after surgery is very important.

Keywords: Bupivacaine; Pain relief; Lumbar decompression surgery

\section{Introduction}

Lumbar decompressive surgery is indicated whenever pain and neural complications of herniated discs, despite conservative treatment, continue. Lumbar decompression is a common procedure for treatment of spine pathology [1]. Despite progresses in realizing postoperative acute pain entity in recent decades, still $80 \%$ of patients suffer from pain after surgery [2]. Undermanaged pain could lead to depression, autonomic over-reaction and joints stiff ness $[3,4]$. Post laminectomy pain has been reported to be caused by some potential pathological changes occurring around the nerve tissue such as inflammation, edema, fibrosis and mechanical pressure on the posterior longitudinal ligament and central sensitization [5]. The origin of lumbar and back pain is irritation of no acceptors and mechanoceptors of vertebrae, discs, duramater, facet capsules, muscles and ligaments $[3,6]$. By activating the 
sympathetic system, uncontrolled postoperative pains may lead to complications and even death. Sympathetic activity increases myocardial oxygen consumption and causes cardiac ischemia and infarction [7]. Sympathetic activity may also decrease gastro-intestinal motility and depth of inspiration leading to paralytic ileus and respiratory complications [7]. Administration of non-steroidal anti-inflammatory drugs (NSAIDs) and opioids is a common method in postoperative pain control [8]. Using opioids alone in not effective in reducing these types of pains, so different drugs including corticosteroids and local anesthetics are also noted [9]. Although analgesics are usually used to control moderate to severe post discectomy pains, but their side effects reduce their applying range [4]. Local anesthetics affect cell wall proteins and inhibit secretion and activity of prostaglandins and nociceptors stimulating lysosome enzymes [10]. On the other way, local anesthetics, by inhibiting the $\mathrm{Na}$ pumps, block the transit of neural messages along the nerve [11].

Local anesthetics for reducing pain Decreases the high costs of anti-inflammatory drugs, opioids and infusion pumps. Local infiltration of bupivacaine is a known method of postoperative pain reduction in many other surgical specialties effective in some [12,13], noneffective in others $[14,15]$. Combination of long acting anesthetic agent and corticosteroid can reduce postoperative discomfort [16]. As there are limited numbers of such studies in our country, we decided to perform the study to see whether it could lead to better pain control or not.

\section{Matrials and Methods}

This is a double blind randomized clinical trial performed on 50 patients with disc herniation and canal stenosis, referring to Rajaee hospital, Qazvin (2019), to evaluate the effects of local injection of bupivacaine in reducing postoperative pain. This study approved by ethical committee of Qazvin University of Medical Sciences with ethical number of IR.QUMS.REC.1395.119.

There is no conflict with ethical considerations. Also, the re- search protocol was approved by the Iranian Registry of Clinical Trials (IRCT2017020625676N8). After signing the personal testimonial papers of participating in the clinical trial, 50 patients (class ASA I and II) randomly entered in groups: interventional and control. The interventional group (25 patients) was injected sub dermal and intramuscular bupivacaine and the control group (25 patients) received only normal saline in the same way. Addicted patients and those with surgery duration more than 2.5 hours were omitted from the study. At the end of operation in the interventional group, bupivacaine $0.25 \%$ and in the control group, $40 \mathrm{ml}$ normal saline were infiltrated subdermally and intramuscularly while the surgeon and educated nurse were not aware of the type of drugs injected. Before surgery, the patients were educated to use VAS (visual analogue scale) to point their postoperative pain severity. Pain severity was registered at hours 3,12 and 24 by educated personnel (either nurse or physician). For those patients with VAS $\geq 4$ morphine was injected intravenously and the dose used were documented in the clinical dossier.

\section{Statistical method}

Kai score was used for qualitative factors analysis, T-test two independent samples, for quantitative factors and repetitive measures in SPSS-22 software was used for evaluation of pain intensity during different periods of time.

\section{Results}

Information of 50 patients were analyzed. 26 (52\%) received bupivacaine and 24(48\%) received normal saline. In bupivacaine group the average age was $43.62 \pm 11.41$ and in saline group was $44.54 \pm 15.25$. Age range of patients was 25-72 years. 11 men (45.8\%) and 15 women (57.7\%) received bupivacaine. 13 men (54.2\%) and 11 women (42.3\%) received saline. There was no significant difference in regard to age $(\mathrm{P}=0.191)$ and gender $(\mathrm{P}=$ 0.290 ) between the two groups. Other patient characteristics are shown in Table 1.

Table 1: Demographic characteristics of two groups.

\begin{tabular}{|c|c|c|c|c|}
\hline Parameter & Rank & Bupivacaine & Normal Saline & P-Value \\
\hline age & $<42$ & $(4 / 44 \%) 12$ & $(6 / 55 \%) 15$ & $191 / 0$ \\
\hline$>42$ & $(9 / 60 \%) 14$ & $(1 / 39 \%) 9$ & & \\
\hline Operated side & unilateral & $(7 / 66 \%) 2$ & $(3 / 33 \%) 1$ & $531 / 0$ \\
\hline bilateral & $(1 / 51 \%) 24$ & $(9 / 48 \%) 23$ & & \\
\hline Operated levels & One level & $(3 / 54 \%) 19$ & $(7 / 45 \%) 16$ & $426 / 0$ \\
\hline More than one level & $(7 / 46 \%) 7$ & $(3 / 53 \%) 8$ & & \\
\hline operation duration & $<80 \min$ & $(1 / 57 \%) 16$ & $(9 / 42 \%) 12$ & $296 / 0$ \\
\hline$>80 \mathrm{~min}$ & $(5 / 45 \%) 10$ & $(5 / 54 \%) 12$ & & \\
\hline Analgesic dose & - & $41 / 3 \pm 53 / 4$ & $64 / 3 \pm 25 / 5$ & $479 / 0$ \\
\hline Pain severity (3 hours after operation) & - & $46 / 2 \pm 08 / 5$ & $15 / 2 \pm 88 / 4$ & $760 / 0$ \\
\hline Pain severity (12 hours after operation) & - & $05 / 2 \pm 73 / 3$ & $15 / 2 \pm 75 / 3$ & $974 / 0$ \\
\hline Pain severity (24 hours after operation) & - & $65 / 1 \pm 19 / 2$ & $61 / 1 \pm 42 / 2$ & $629 / 0$ \\
\hline
\end{tabular}

No significant difference at 3,12 and 24 hours were noted in the two groups (Table 2). We did not find significant difference in average pain severity between the two groups but in each group, pain severity during 24 hours after operation, decreased signifi- 
cantly ( $\mathrm{p}=0.0001<0.05)$ ) Figure 1$)$. Although during 12 to 24 hours after operation, bupivacaine reduced pain severity but, in both groups, changes in pain severity were close and showed no statistical difference $(\mathrm{P}=0.441)$. Also, whole pain average during 24 hours after operation, was $3.66 \pm 0.35$ in bupivacaine group and $3.68 \pm 0.36$ in saline group. So, no significant difference were found between the two groups $(\mathrm{P}=0.978$ ((Figure 1$)$.

Table 2: Comparison of groups regarding different parameters.

\begin{tabular}{|c|c|c|c|c|c|c|c|}
\hline \multirow{2}{*}{\multicolumn{2}{|c|}{$\begin{array}{c}\text { Parameter } \\
3 \text { hours }\end{array}$}} & \multicolumn{3}{|c|}{ Bupivacaine } & \multicolumn{3}{|c|}{ Normal Saline } \\
\hline & & 12 hours & 24 hours & 3 hours & 12 hours & 24 hours & \\
\hline \multirow{3}{*}{ gender } & male & $91 / 1 \pm 36 / 2$ & $11 / 2 \pm 36 / 3$ & $29 / 2 \pm 45 / 4$ & $86 / 0 \pm 08 / 2$ & $75 / 1 \pm 62 / 3$ & $55 / 1 \pm 38 / 4$ \\
\hline & female & $48 / 1 \pm 07 / 2$ & $03 / 2 \pm 4$ & $56 / 2 \pm 53 / 5$ & $18 / 2 \pm 82 / 2$ & $62 / 2 \pm 91 / 3$ & $65 / 2 \pm 45 / 5$ \\
\hline & P-value & $659 / 0$ & $446 / 0$ & $279 / 0$ & $310 / 0$ & $747 / 0$ & $233 / 0$ \\
\hline \multirow{3}{*}{ age } & $<42$ & $41 / 2 \pm 25 / 5$ & $22 / 2 \pm 67 / 3$ & $44 / 1 \pm 92 / 1$ & $18 / 2 \pm 73 / 4$ & $05 / 2 \pm 67 / 3$ & $52 / 1 \pm 20 / 2$ \\
\hline & $>42$ & $58 / 2 \pm 93 / 4$ & $96 / 1 \pm 79 / 3$ & $82 / 1 \pm 43 / 2$ & $21 / 2 \pm 11 / 5$ & $42 / 2 \pm 89 / 3$ & $78 / 1 \pm 78 / 2$ \\
\hline & P-value & $748 / 0$ & $886 / 0$ & $441 / 0$ & $678 / 0$ & $813 / 0$ & $408 / 0$ \\
\hline \multirow{3}{*}{ Operated levels } & One level & $52 / 2 \pm 84 / 4$ & $09 / 2 \pm 53 / 3$ & $80 / 1 \pm 16 / 2$ & $24 / 2 \pm 88 / 4$ & $25 / 2 \pm 4$ & $41 / 1 \pm 38 / 2$ \\
\hline & More than one level & $36 / 2 \pm 71 / 5$ & $97 / 1 \pm 29 / 4$ & $25 / 1 \pm 29 / 2$ & $10 / 2 \pm 88 / 4$ & $98 / 1 \pm 25 / 3$ & $07 / 2 \pm 5 / 2$ \\
\hline & P-value & $435 / 0$ & $413 / 0$ & $865 / 0$ & 0.999 & $433 / 0$ & $863 / 0$ \\
\hline \multirow{3}{*}{ operation duration } & $<80 \min$ & $74 / 2 \pm 25 / 5$ & $16 / 2 \pm 8 / 3$ & $86 / 1 \pm 44 / 2$ & $02 / 2 \pm 42 / 4$ & $15 / 2 \pm 42 / 3$ & $40 / 1 \pm 17 / 2$ \\
\hline & $>80$ min & $04 / 2 \pm 8 / 4$ & $95 / 1 \pm 6 / 3$ & $22 / 1 \pm 8 / 1$ & $27 / 2 \pm 33 / 5$ & $19 / 2 \pm 08 / 4$ & $82 / 1 \pm 67 / 2$ \\
\hline & P-value & $638 / 0$ & $803 / 0$ & $348 / 0$ & $307 / 0$ & $460 / 0$ & $460 / 0$ \\
\hline
\end{tabular}

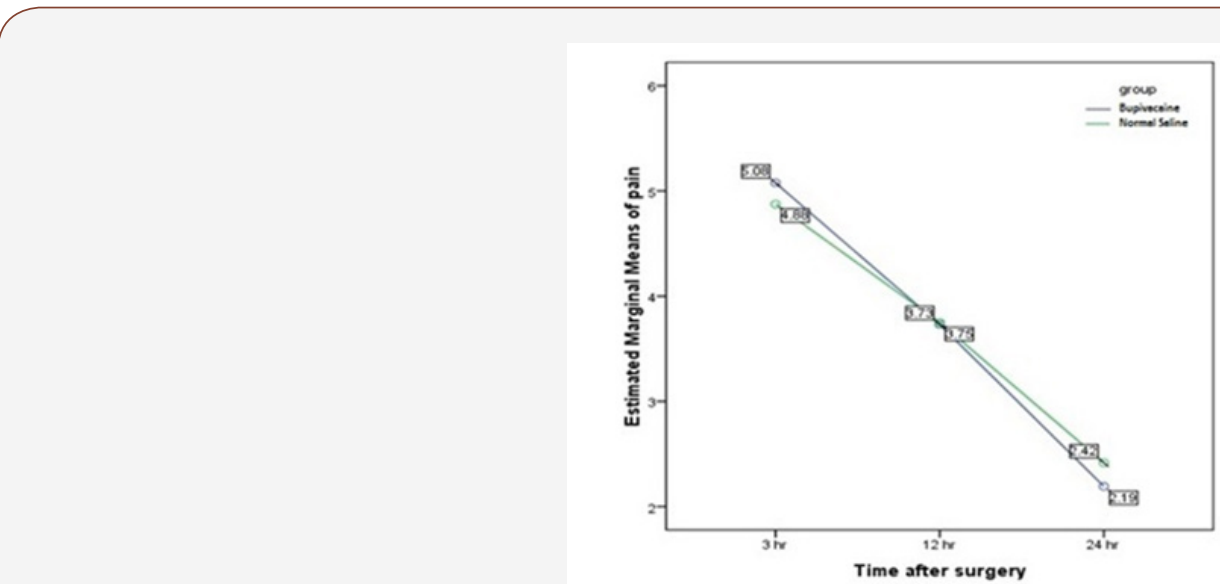

Figure 1: Mean of decrease pain at time of postoperative surgery.

The effect of bupivacaine on pain reduction in regard to patients' characteristics were not significant but in women and in ages below 42 and also in patients with one level surgery and operations lasting more than 80 minutes, bupivacaine mildly reduced the pain during 24 hours after operation.

\section{Discussion}

In this study, we compared the effects of bupivacaine and saline (as placebo) injection in time intervals and found no significant differences in the two study groups, with regard to mean age, gender distribution, pain relief and analgesic drug requirement. Cook and Mullen (1979) firstly suggested local bupivacaine injection for lumbar post laminectomy pain relief. Teddy et al (1981) in a double-blind clinical trial found no significant difference in VAS grading postoperative pain in "case" and "control" groups [17]. Rahmanian et al study (2015) also showed no significant difference in pain relief in "bupivacaine" and "saline" groups [18]. Donadi et al (2017) concluded that the local injection of magnesium sulfate and bupivacaine provided better pain control and analgesic effect was more significant [5]. Steel et al (1998) concluded that bupivacaine can reduce patients' pain score by more than $50 \%$ in the recovery room [19].

A reliable study to show the individual effects of bupivacaine on nociceptors is not available yet. Although in the present study normal saline $0.9 \%$ is supposed to be none effective on nociceptors but it may reduce the pain by decreasing the concentration of inflammatory mediators. Saline may also compress the nerve end- 
ings, thereby blocking the conduction of nerve pulses and producing analgesia [20]. In study on cats (2007) normal saline was none effective on thermal, electrical and pressures no inceptor's [21].

In some studies, bupivacaine alone or in a combination with other drugs has been reported to be effective in reducing postoperative pain and the length of postoperative hospital stay [5]. Some recent studies have shown effectiveness of pregabalin in reducing pain and postoperative anxiety [22-24].

\section{Conclusion}

With regard to previous studies and our present study, although bupivacaine alone had the effectiveness dose at less pain post-surgery, performing wider studies on the effect of bupivacaine combined with other drugs is suggested in lumbar spine surgery.

\section{Acknowledgement}

None.

\section{Conflict of Interest}

No conflict of interest.

\section{References}

1. Apfelbaum JL, Chen C, Mehta SS, Gan TJ (2003) Postoperative pain experience: results from a national survey suggest postoperative pain continues to be undermanaged. Anesthesia \& Analgesia. 97(2): 534540 .

2. Boezaart AP, Munro AP, Tighe PJ (2013) Acute pain medicine in anesthesiology. F1000Prime Reports. 3(5): 54.

3. Coley KC, Williams BA, DaPos SV, Chen C, Smith RB (2002) Retrospective evaluation of unanticipated admissions and readmissions after same day surgery and associated costs. Journal of clinical Anesthesia 14(5): 349-353.

4. Dolin SJ, Cashman JN (2005) Tolerability of acute postoperative pain management: nausea, vomiting, sedation, pruritus, and urinary retention. Evidence from published data. British Journal of Anaesthesia. 95(5): 584-549.

5. Donadi PK, Moningi S, Gopinath R (2014) Comparison of bupivacaine and bupivacaine plus magnesium sulphate infiltration for postoperative analgesia in patients undergoing lumbar laminectomy: A prospective randomized double-blinded controlled study. Journal of Neuroanaesthesiology and Critical Care 1(3): 183-187.

6. Engelman E, Cateloy F (2011) Efficacy and safety of perioperative pregabalin forpost-operative pain: a meta-analysis of randomizedcontrolled trials. Acta Anaesthesiol Scand. 55(8): 927-943.

7. Glasser RS, Knego RS, Delashaw JB, Fessler RG (1993) The perioperative use of corticosteroids and bupivacaine in the management of lumbar disc disease. Journal of Neurosurgery 78(3): 383-387.

8. Grieff AN, Ghobrial GM, Jallo J (2016) Use of liposomal bupivacaine in the postoperative management of posterior spinal decompression. J Neurosurg SpineJournal of Neurosurgey Spine 25(1): 88-93
9. Hegarty DA, Shorten GD (2011) A randomised, placebo-controlled trial of theeffects of preoperative pregabalin on pain intensity and opioid consumptionfollowing lumbar discectomy. Korean Journal of Pain 24(1): 22-30.

10. Jonnavithula N, Khandelia H, Durga P, Ramachandran G (2015) Role of wound instillation with bupivacaine through surgical drains for postoperative analgesia in modified radical mastectomy. Indian Journal of Anesthesia 59: 15-20.

11. Karla P, Miller RD (2010) Anesthesia: Acute postoperative pain ( $7^{\text {th }}$ edn). Churchill Livingstone, New York, USA, pp. 2758-59.

12. Mathieson S, Maher CG, McLachlan AJ, Latimer J, Koes BW, et al. (2013) PRECISE-pregabalin in addition to usual care for sciatica: study protocolfor a randomised controlled trial. Trials 14: 213.

13. Mordeniz C, Torun F, Soran AF, Beyazoglu O, Karabag H, et al. (2010) The effects of pre-emptive analgesia with bupivacaine on acute postlaminectomy pain. Archives of Orthopaedic and Trauma Surgery 130(2): 205-208.

14. Morrison I, Perini I, Dunham J (2013) Facets and mechanisms of adaptive pain behavior: predictive regulation and action. Frontiers in Human Neuroscience 7: 755.

15. Mullen JB, Cook WA (1979) Reduction of postoperative lumbar hemi laminectomy pain with Marcaine: technical note. Journal of neurosurgery 51(1): 126-127.

16. Nasseh N, Khezri M (2015) Effects of adding midazolam to intrathecal bupivacaine on pain after cesarean section. Journal of Qazvin University of Medical Sciences 19(1): 4-10.

17. Rahmanian A, Malekpour F, Rakei SM, Ghaffarpasand F, Mehrabani G (2016) The Effects of Bupivacaine on Postoperative Back Pain after Lumbar Laminectomy: A Randomized Clinical Trial. Neurosurgery Quarterly 26(4): 293-297.

18. Sinatra R (2010) Causes and consequences of inadequate management of acute pain. Pain Medicine. 11(12): 1859-1871.

19. Steagall PV, Taylor PM, Brondani JT, Luna SP, Dixon MJ, et al. (2007) Effects of buprenorphine, carprofen and saline on thermal and mechanical nociceptive thresholds in cats. Veterinary anaesthesia and analgesia 34(5): 344-350.

20. Steel T, Jones R, Crossman J, Sheehy J, Bentivoglio P, et al. (1998) Intraoperative wound infiltration with bupivacaine in patients undergoing lumbar spine surgery. Journal of Clinical Neuroscience 5(3): 298-303.

21. Tavakol K, Daneshi AAH, Karimzadeh Shirazi K (2008) Effect of Instillation of Morphine and Dexamethasone in Epidural Space on postoperative pain in discectomy operation. Armaghan danesh journal. 12(1): 107-115.

22. Teddy P, Fabinyi GC, Kerr JH, Briggs M (1981) Bupivacaine infiltration after lumbar laminectomy. Anesthesia 36(4): 380-383.

23. White PF, Tufanogullari B, Taylor J, Klein K (2009) The effect of pregabalin onpreoperative anxiety and sedation levels: a dose-ranging study. Anesthesia Analg 108(4): 1140-1145.

24. Zarei M, Najafi A, Mansouri P, Sadeghi-Yazdankhah S, Saberi H, et al. (2016) Management of postoperative pain after Lumbar surgerypregabalin for one day and 14 days-a randomized, triple-blinded, placebo-controlled study. Clinical \& Neurological Neurosurgery 151: $37-42$. 